\title{
Analysis on Evolutionary Stability Strategies of Carbon Emission of Logistics Enterprises Based on Carbon Tax
}

\author{
Xiaoping Wu $(\mathbb{D}$, Peng Liu $(\mathbb{D}$, and Qi Wei $(\mathbb{D})$ \\ Xi'an University of Posts and Telecommunications, Xi'an 710061, Shaanxi, China \\ Correspondence should be addressed to Peng Liu; liupeng92017@126.com
}

Received 31 March 2021; Revised 15 October 2021; Accepted 2 November 2021; Published 2 December 2021

Academic Editor: Ricardo Aguilar-Lopez

Copyright (C) 2021 Xiaoping Wu et al. This is an open access article distributed under the Creative Commons Attribution License, which permits unrestricted use, distribution, and reproduction in any medium, provided the original work is properly cited.

In view of the problem of high carbon emissions of logistics enterprises, the government's carbon tax policy, consumers' willingness to purchase low-carbon services, and the carbon emission reduction behavior of logistics enterprises, the evolutionary game model between the government, consumers, and logistics enterprises is established by using the theory and method of evolutionary game, and the evolutionary stabilization strategies of the three parties under different parameters are analyzed. The research results show the following. (1) When setting the carbon tax rate, the government can ignore the impact on consumers and give more consideration to the influencing factors of logistics enterprises, which is conducive to the formulation of carbon emission reduction policies for logistics enterprises. (2) When the government sets a lower carbon tax rate, it can not only promote the carbon emission reduction of logistics enterprises but also be conducive to government supervision. (3) The evolution direction of the government's final decision will not change due to the size of $Y$ and $Z$. The government's final decision is to adopt a regulatory strategy. The study provides theoretical guidance for the government to formulate carbon tax policies, guides consumers to purchase low-carbon services, and promotes carbon emission reduction in logistics enterprises.

\section{Introduction}

The accelerating process of global warming has attracted more and more social attention and is gradually becoming one of the main topics of global concern. According to the Global Energy Review, carbon dioxide emissions in 2020 were released by the International Energy Agency; global carbon emissions decreased by $5.8 \%$ in 2020 , the largest decrease in global carbon emissions since 1945. Although there are significant results in the management of global carbon emissions, there is still widespread concern about the pollution of the environment from carbon emissions. China is the world's largest emitter of carbon emissions, accounting for about $13.8 \%$ of global carbon emissions. On September 22,2020 , the Chinese government proposed the following at the 75th session of the United Nations General Assembly: "China will enhance its national autonomous contribution, adopt more powerful policies and measures, strive to reach the peak of carbon dioxide emissions by 2030 and strive to achieve carbon neutralization by 2060 [1]." On March 5,
2021, the State Council government work report pointed out that the work of carbon neutrality and carbon peaking should be done solidly, and the action plan of carbon peaking by 2030 should be formulated to optimize the industrial structure and energy structure [2].

At present, more than 40 countries around the world have integrated carbon taxes with low-carbon economies. Among them, Portugal stipulates that the carbon tax rate is linked to the carbon price of the EU carbon trading system, and its carbon tax will be increased from $\$ 8.50$ to $\$ 14.30$ in early 2019; Canada has imposed a carbon tax at $\$ 15$ per ton since 2019 and proposes raising it to $\$ 38$ per ton in 2022. In 2017, China launched its carbon trading system and replaced the EU as the largest carbon trading market. At the same time, it issued a special report on the "Design of China's Carbon Tax Framework," which put forward specific plans on the carbon tax implementation framework, launch time, and tax rate of carbon tax [3]. Many United Nations Climate conferences have promoted the continuous concretization of institutional arrangements for carbon emission reduction, 
leading governments to formulate different carbon emission reduction policies, such as the carbon boundary measures proposed by the United States, the carbon emission trading system established by the European Union, and the carbon tax policy formulated by Denmark.

The scale of China's logistics market has surpassed the United States to become the world's largest. 54\% of the carbon dioxide emissions generated by the transportation industry are generated by truck transportation. According to the "Measurement Method of Greenhouse Gas Emissions in Logistics Industry" issued by the State Post Office in 2018, the total energy consumption of transportation, storage, and postal industry in 2018 was 436.17 million tons of standard coal, which caused serious air pollution. Therefore, improving the current situation of high carbon emissions in the logistics industry not only conforms to the call of the government to protect the ecological environment but also promotes the development of the logistics industry to low carbon. However, the vast majority of logistics enterprises have relatively weak awareness of the low-carbon economy. In order to pursue high profits and save transportation costs, logistics enterprises often choose high carbon emission transportation. As the promulgator of low-carbon policy and the supervisor of low-carbon behavior, the government must supervise and regulate the low-carbon behavior of logistics enterprises [3].

This paper introduces consumers as the third game subject and considers the carbon emission decision problem of logistics enterprises from two perspectives: market regulators and market consumers. Therefore, this paper still aims at the problem of whether logistics enterprises adopt carbon emission reduction measures. On the one hand, it considers many external factors, that is, the government takes carbon tax and other policies as the constraint mechanism for carbon emission of logistics enterprises, and the choice of consumer behavior will have an impact on the logistics market. On the other hand, under the influence of many external factors, it considers whether logistics enterprises will take carbon emission reduction measures and under what conditions can they achieve the balance of the three strategies. According to the above elaboration, this paper uses the evolutionary game theory to construct a three-party evolutionary game model for carbon emission reduction among government, consumers, and logistics enterprises and analyzes the strategy selection and final evolutionary stability strategy of the three under different conditions. The research results provide a powerful reference for the government to formulate a reasonable carbon tax policy.

This paper is divided into six parts: introduction, literature review, basic assumptions and symbolic description, construction and analysis of the evolutionary game model, analysis, and conclusion of evolutionary stability strategy.

\section{Literature Review}

2.1. Literature Review on Carbon Tax. At present, most domestic and foreign scholars believe that the government's adoption of a carbon tax policy can effectively promote enterprises to reduce carbon emissions. Therefore, domestic and foreign scholars have conducted a large amount of research on the government's adoption of carbon tax policy from the aspects of environmental protection, economic benefits, and energy consumption. For example, Pearce [4] used a theoretical model to demonstrate that carbon tax plays a dual role in promoting employment, environment, and economic improvement.

Katsoulacos and Xepapadeas [5] show that only when the government adopts a carbon tax policy can enterprises be encouraged to develop low-carbon technologies. Ahmad and Wyckoff [6] believe that if other taxes of enterprises can be reduced, the adverse impact of a carbon tax on enterprise output and competitiveness will be reduced. Wissema and delllink [7] believe that Ireland's carbon tax has a significant gain effect on carbon emission reduction, government revenue increase, and energy consumption promotion. Metcalf [8] and Wittneben [9] believe that carbon tax can be adjusted flexibly according to the needs of emission reduction. Zhu and Geng [10] believe that carbon emission tax can stimulate enterprises to actively implement carbon emission reduction. Yu and Zhang [11] compared unified and differentiated carbon taxes and found that differentiated carbon taxes can promote low-carbon enterprises. Tang [12] studied the behavior game of government and enterprises on emission reduction in the green supply chain based on Nash equilibrium theory and evolutionary game theory. $\mathrm{Xu}$ [13] studied the strategy of controlling the government, automobile enterprises, and residents to finally achieve evolutionary stability.

However, some scholars believe that the government's adoption of carbon tax policy only has an adverse effect on economic development. For example, Batabyal [14] found that carbon tax will inhibit the increase of profits by constructing the Stackelberg game model and Cournot model. Lee et al. [15] and Frank [16] proposed that other policies could be combined with a carbon tax to have a positive impact on GDP. Taking Taiwan as an example, Lee et al. [15] and others found that carbon tax would reduce the GDP growth rate. Lang and Zheng [17] and others proposed that the introduction of the carbon tax in China would improve the output efficiency of energy factors and inhibit economic growth.

Therefore, some scholars have combined carbon tax with government subsidies and found that it has a great impact on economic improvement and low-carbon energy reduction. For example, Lim and Kim [18] found that if the government associates R\&D subsidies with the carbon tax, it will increase the real GDP without increasing carbon dioxide emissions. Meltzer [19] believes that subsidies for clean technology $\mathrm{R} \& \mathrm{D}$ and other measures are conducive to reducing carbon dioxide emissions. Guojun and $\mathrm{Hu}$ [20] discussed the changes in the difficulty of carbon emission reduction at different development stages and discussed whether the corresponding subsidy measures can promote carbon emission reduction. Yi [21] found that subsidies for energysaving products stimulated enterprises to reduce carbon emissions and energy consumption. Wang [22] found that government subsidies can better improve members' profits 
and government utility and promote the development of a circular economy and a green economy.

However, the subjects considered by the above scholars are relatively single. They either study the impact of the carbon tax on government finance or enterprise production, and the industries studied by the above scholars do not involve the logistics industry.

\subsection{Literature Review on Multiagent Carbon Emission} Reduction. Some scholars at home and abroad use the evolutionary game model to consider the relationship between government and enterprises and study the impact of rising carbon tax or providing low-carbon subsidies on the government and enterprises. For example, Wang et al. [23] discussed the realization and policy analysis of the static game and the dynamic evolutionary game between government and enterprises under a low-carbon economy. Zhu et al. [24] established the evolutionary game between government and enterprises to analyze whether the two sides adopted the evolutionary stability strategy of carbon emission reduction measures. Chen and Wang [25] concluded that increasing tax rates and strengthening supervision are conducive to reducing pollution emissions of enterprises by building an evolutionary game model. Liu et al. [26] constructed an evolutionary game model of government and enterprises and analyzed the impact of punishment cost and low-carbon subsidy on the strategic choice of government and enterprises. Jiao et al. [27] analyzed the impact of carbon quota, carbon price, government supervision cost, and enterprise emission reduction investment on the relationship between government and enterprises in emission reduction areas by using the evolutionary game method. Liu Changyu [28] compared and analyzed the differences in the conditions required by the government and manufacturers to achieve equilibrium under different regulatory policies from a low-carbon perspective. Chen and Chen [29] found that the carbon emission reduction level of manufacturers, the market price of unit products, and total social welfare under the government subsidy mode are better than those without the subsidy model.

Later, on the basis of the evolutionary game between the government and enterprises, many scholars joined the consumer as the game subject. Therefore, scholars at home and abroad generally used the evolutionary game model to study the relationship between the government, enterprises, and consumers in carbon emission and found the optimal solution or stability strategy selected by the three according to their own interests and needs, such as $\mathrm{Xu}$ and $\mathrm{Lv}$ [30] incorporated the public, enterprises, and government, the main bodies of low-carbon economic construction, into the game model analysis system to find the evolution path and stability strategy of different subjects. Sun and Chang [31], based on incentive compatibility theory and game theory, studied and obtained the key points of the government in formulating incentive policies for enterprises and consumers. Tian et al. [32] used evolutionary game theory to analyze the relationship among stakeholders such as government, enterprises, and consumers and built a system dynamics (SD) model to guide subsidy policies. Chang et al. [33] established a tripartite game model involving the government, pollutant discharge enterprises, and the public and analyzed the stability of stakeholder interaction through system dynamics dynamic simulation. Wu et al. [34] discussed the impact of carbon tax policy on the tripartite strategic choice by constructing a tripartite evolutionary game model of government and enterprises under dual regulation. Li et al. [35] found the balance point among consumers, enterprises, and government through game analysis and built a reasonable low-carbon consumer guidance mechanism in combination with consumer behavior theory. Lv et al. [36] and others established a closedloop supply chain network equilibrium model with consumers' low-carbon preference under the government's carbon tax and subsidy policies. Tang [37] studied the optimal proportion of carbon tax levied by the government on enterprises and consumers by using the Stackelberg game model.

Through the above literature review, it can be concluded that there are fewer studies on low-carbon evolutionary games based on carbon tax and fewer articles on carbon emission in the logistics industry. This paper innovatively introduces consumers as the main subject of low-carbon behavior research in the logistics industry and combines government carbon tax and consumer preference to achieve the innovation of research background and research subject. Considering the external factors such as the impact of government carbon tax policy as a regulatory tool and the impact of consumer preferences on the logistics market, this paper studies the carbon emission of logistics enterprises. Firstly, it studies the choice of carbon emission strategy and evolutionary stability strategy of logistics enterprises under the influence of a single external factor of a government carbon tax. Secondly, it studies the choice of carbon emission strategy of logistics enterprises under the influence of government carbon tax and consumer preference and analyzes the tripartite evolutionary stability strategy. Finally, the optimal solution of the government and logistics enterprises' decision-making under different external environments is studied.

\section{Problem Description and Model Building}

3.1. Problem Description. This paper introduces the consumer as the third main body of the game and studies the carbon emission decision-making of express enterprises from the perspective of market regulators and market consumers. Therefore, this paper is still aimed at the problem of whether express enterprises take carbon emission reduction measures. On the one hand, it considers many external factors, that is, the government takes carbon tax and other policies as the constraint mechanism of carbon emissions of express enterprises, and consumer behavior choice will affect the express market. On the other hand, under the influence of many external factors, whether 
express enterprises will take carbon emission reduction measures and under what conditions they can achieve the balance of the three strategies are considered. According to the above elaboration, we consider how to reasonably set the parameters and assumptions of the three parties and use the evolutionary game theory to build a tripartite evolutionary game model of carbon emission reduction of the government, consumers, and express enterprises, analyze the strategy choice of the three parties under different conditions and the final evolutionary stability strategy, how to effectively promote the express enterprises to take measures to reduce carbon emissions, and finally realize the goal of carbon environmental protection and low-carbon emission of express enterprises.

\subsection{Basic Assumptions}

Hypothesis 1. The development of low-carbon express delivery requires the participation of all aspects of society. Therefore, the participants in the model are the government, express delivery enterprises, and consumers, and all of them are bounded rationality, pursuing the maximization of their own interests.

Hypothesis 2. The government can choose whether to supervise or not; that is, the strategic space is (supervision, nonsupervision); the express enterprises can choose to implement or not; that is, the strategic space is (implementation, nonimplementation). Consumers have the right to choose to buy or not to buy a low-carbon service strategy, and the strategy space is (purchase, nonpurchase).

Hypothesis 3. The cost of express delivery enterprises in the nonimplementation of low-carbon strategy (traditional express mode) is $c_{0}$, income is $R_{1}$, and carbon emissions (including direct and indirect emissions) are $e_{0}$. The increased costs of express delivery enterprises in the implementation of low-carbon strategy increased costs (including technology $\mathrm{R} \& \mathrm{D}$ innovation costs and equipment costs) are $c, c=1 / 2 \beta e^{2}[29,38]$, where $\beta$ is the cost coefficient of carbon reduction for express delivery enterprises, $e$ is the carbon emission reduction, the income is $R_{2}$, and the express delivery enterprises after the reduction of carbon emissions (including direct and indirect emissions) are $e_{1}, e_{0}>e_{1}$.

Hypothesis 4. The cost for the government to choose regulation is $c_{1}$. When express delivery enterprises implement a low-carbon strategy, the environmental governance cost of the government is $c_{2}, c_{2}=\eta e_{1}$. When express delivery enterprises do not implement a low-carbon strategy, the environmental governance cost of the government is $c_{5}$, $c_{5}=\eta e_{0} ; \eta$ is the environmental governance cost coefficient and $c_{3} \geq c_{2}$. When the government chooses regulation, the government's incentive subsidy for carbon emission reduction of express delivery enterprises implementing lowcarbon strategy is $s, s=\theta c$ [29], where $\theta$ is the subsidy coefficient and $0<\theta<1 ; p(p=\gamma e[34])$ is the punishment for express delivery enterprises that do not implement lowcarbon strategy, and $\gamma$ is the penalty coefficient.

Hypothesis 5. The direct benefits of consumers' purchase of low-carbon express and traditional express services are the same, and the differences are mainly reflected in the indirect benefits, such as green, environmental protection, and sustainable development. Therefore, when consumers do not buy low-carbon express service, that is to say, the cost of choosing not to implement low-carbon express service is $c_{3}$, and the income is $R_{3}$. The cost of low-carbon express service is $c_{4}\left(c_{3}<c_{4}\right)$ and the income is $R_{4}\left(R_{3}<R_{4}\right)$. At the same time, the government will take part of the subsidies given to express enterprises to reward consumers who buy lowcarbon express as $b s, b$ as subsidy proportion, and $0<b<1$.

Hypothesis 6. The government can detect the carbon emissions of express delivery companies when it adopts a regulatory strategy and levy carbon tax on the carbon emission of express delivery enterprises, and the carbon tax rate is t; when the government does not regulate, both sides do not consider carbon emissions and carbon taxes.

Based on the above assumptions, the income matrix of eight strategy combinations is obtained, as shown in Tables 1 and 2.

\section{Model Solution and Analysis}

Suppose that, at the beginning of the game, the probability of the government choosing regulation is $x$ and the probability of nonregulation is $1-x$. The probability of implementing a low-carbon strategy in express delivery enterprises is $y$, and the probability of not implementing a low-carbon strategy is $1-y j$ The proportion of consumers who choose to buy strategy is $z$ and the proportion who do not buy low-carbon express service strategy is $1-z$.

And $0 \leq x \leq 1,0 \leq y \leq 1,0 \leq z \leq 1$.

The expected revenue from government supervision and nonsupervision is $U_{G}^{Y}$ and $U_{G}^{N}$, respectively, and the average expected revenue of government is $E U_{G}$ :

$$
\begin{aligned}
U_{G}^{Y}= & y z\left(t e_{1}-c_{1}-s-c_{2}\right) \\
& +(1-y) z\left(t e_{0}-c_{1}-c_{5}-b s+p\right)+ \\
& y(1-z)\left[t e_{1}-c_{1}-(1-b) s-c_{2}\right] \\
& +(1-y)(1-z)\left(t e_{0}-c_{1}-c_{5}+p\right), \\
U_{G}^{N}= & y z\left(-c_{2}\right)+(1-y) z\left(-c_{5}\right) \\
& +y(1-z)\left(-c_{2}\right)+(1-y)(1-z)\left(-c_{5}\right), \\
E U_{G}= & x U_{G}^{Y}+(1-x) U_{G}^{N} .
\end{aligned}
$$

The dynamic replication equation when the government chooses a regulatory strategy is $F(x)=d x / d t=x\left(U_{G}^{Y}-\right.$ $\left.E U_{G}\right)=x(1-x)\left(U_{G}^{Y}-U_{G}^{N}\right)=x(1-x)\left[y\left(t e_{1}-t e_{0}-(1-\right.\right.$ $\left.b) s-p)-z b s+\left(t e_{0}-c_{1}+p\right)\right](1-1)$.

The proof of replication dynamic equation: the dynamic change of the proportion of the strategy type of the game 
TABLE 1: Specification of model parameters.

\begin{tabular}{lc}
\hline Symbol & Significance \\
\hline$c_{2}$ & Low-carbon government environmental cost \\
$c_{5}$ & Non-low-carbon government environmental governance cost \\
$e_{0}$ & Carbon emissions of non-low-carbon logistics enterprises \\
$e$ & Carbon emissions of low-carbon logistics enterprises \\
$c_{4}$ & Consumer cost of choosing low-carbon logistics \\
$R_{4}$ & Consumer benefits of low-carbon logistics \\
$c_{3}$ & Non-low-carbon logistics consumer cost \\
$R_{3}$ & Non-low-carbon logistics consumer benefits \\
$c$ & Enterprise cost of implementing low-carbon \\
$\eta$ & Environmental governance cost coefficient \\
$c_{0}$ & Non-low-carbon strategy enterprise cost \\
$R_{1}$ & Non-low-carbon strategy enterprise income \\
$R_{2}$ & Enterprise benefits of implementing low-carbon \\
$\beta$ & Carbon emission reduction cost coefficient \\
$e_{1}$ & Carbon emissions after emission reduction \\
$\theta$ & Subsidy coefficient of logistics enterprises \\
$s$ & Government incentives and subsidies \\
$c_{1}$ & Government supervision cost \\
$b s$ & Government incentives for consumers \\
$p$ & Non-low-carbon punishment \\
$t$ & Carbon tax rate \\
$b$ & Subsidy comparison \\
$\gamma$ & Penalty coefficient
\end{tabular}

TABLE 2: Income matrix of tripartite game.

\begin{tabular}{lccc}
\hline Strategy combination & Government revenue & Income of express enterprises & Consumer benefits \\
\hline (Supervision, implementation, purchase) & $t e_{1}-c_{1}-s-c_{2}$ & $R_{2}-c_{0}-c-t e_{1}+(1-b) s$ & $R_{4}-c_{4}+b s$ \\
(Supervision, implementation, nonpurchase) & $t e_{1}-c_{1}-(1-b) s-c_{2}$ & $(1-b) s-c_{0}-c-t e_{1}$ & 0 \\
(Supervision, nonimplementation, Purchase) & $t e_{0}-c_{1}-c_{5}-b s+p$ & $-c_{0}-p-t e_{0}$ & $b s$ \\
(Supervision, nonimplementation, nonpurchase) & $t e_{0}-c_{1}-c_{5}+p$ & $R_{1}-c_{0}-t e_{0}-p$ & $R_{3}-c_{3}$ \\
(Nonsupervision, implementation, purchase) & $-c_{2}$ & $R_{2}-c_{0}-c$ & 0 \\
(Nonsupervision, implementation, nonpurchase) & $-c_{2}$ & $-c_{0}-c$ & 0 \\
(Nonsupervision, nonimplementation, Purchase) & $-c_{5}$ & $-c_{0}$ & $R_{4}-c_{4}$ \\
(Nonsupervision, nonimplementation, Nonpurchase) & $-c_{5}$ & $R_{1}-c_{0}$ & $R_{3}-c_{3}$ \\
\hline
\end{tabular}

party is the core of bounded rational game analysis, and the key is the speed of dynamic change. This depends on two factors. One is the number of imitation objects (which can be expressed by the proportion of corresponding types of players) because it is related to the difficulty of observation and imitation. The second is the success degree of the imitation object (which can be expressed by the extent that the strategy benefit of the imitation object exceeds the average benefit) because it is related to the difficulty of judging the difference and the size of the imitation incentive.

$$
\frac{d x}{d t}=x\left(u_{y}-\bar{u}\right)
$$

where $x$ is the proportion of the players of a strategy, $u_{y}$ is the expected benefit of adopting a strategy, $\bar{u}$ is the average strategy of all players, and $d x / d t$ is the change rate of the proportion of the players of a strategy over time.
The expected revenue from implementation and nonimplementation of express delivery enterprises is $U_{E}^{Y}$ and $U_{E}^{N}$, and the average expected revenue of express delivery enterprises is $E U_{E}$ :

$$
\begin{aligned}
U_{E}^{Y}= & x z\left[R_{2}-c_{0}-c-t e_{1}+(1-b) s\right] \\
& +x(1-z)\left[(1-b) s-c_{0}-c-t e_{1}\right] \\
& +(1-x)(1-z)\left(-c_{0}-c\right), \\
U_{E}^{N}= & x z\left(-c_{0}-p-t e_{0}\right)+(1-x) z\left(-c_{0}\right) \\
& +x(1-z)\left(R_{1}-c_{0}-t e_{0}-p\right) \\
& +(1-x)(1-z)\left(R_{1}-c_{0}\right), \\
E U_{C}= & z U_{C}^{Y}+(1-z) U_{C}^{N} .
\end{aligned}
$$

The replication dynamic equation when express delivery enterprises choose to implement the strategy is 


$$
\begin{aligned}
F(y) & =\frac{d y}{d t}=\left(y U_{E}^{Y}-E U_{E}\right)=y(1-y)\left(U_{E}^{Y}-U_{E}^{N}\right) \\
& =y(1-y)\left[x\left(t e_{0}-t e_{1}+(1-b) s+p\right)+z\left(R_{1}+R_{2}\right)-R_{1}-c\right] .
\end{aligned}
$$

The expected revenue from consumers' purchase and nonpurchase is $U_{C}^{Y}$ and $U_{C}^{N}$, respectively, and the average expected revenue of consumers is $E U_{C}$ :

$$
\begin{aligned}
U_{C}^{Y} & =x y\left[R_{4}-c_{4}+b s\right]+x(1-y) b s+(1-x) y\left(R_{4}-c_{4}\right), \\
U_{C}^{N} & =x(1-y)\left(R_{3}-c_{3}\right)+(1-x)(1-y)\left(R_{3}-c_{3}\right), \\
E U_{C} & =z U_{C}^{Y}+(1-z) U_{C}^{N} .
\end{aligned}
$$

The replication dynamic equation when consumers choose to purchase strategy is $F(z)=d z / d t=z\left(U_{C}^{Y}-E U_{C}\right)$ $=z(1-z)\left(U_{C}^{Y}-U_{C}^{N}\right)=z(1-z)\left[y\left(R_{3}-c_{3}\right)+x b s+R_{4}-c_{4}\right.$ $\left.-R_{3}+c_{3}\right]$. (1-3)

4.1. Stability Analysis of Government Evolutionary Game. According to the evolutionary game theory, when $F^{\prime}\left(x^{*}\right)<$ $0, x^{*}$ is the government's evolutionary stability strategy (ESS). The following analyzes the government's evolutionary stability strategy in different situations. According to the replication dynamic equation (1) of government regulatory strategy, the derivative with respect to $x$ is $F^{\prime}(x)=(1-2 x)$ $\left[y\left(t e_{1}-t e_{0}-(1-b) s-p\right)-z b s+\left(t e_{0}-c_{1}+p\right)\right]$, so $F^{\prime}(x)$ $=0$ and $y^{*}=t e_{0}-c_{1}+p-z b s / t e_{0}-t e_{1}+(1-b) s+p$.

(1) When $y=y^{*}=t e_{0}-c_{1}+p-z b s / t e_{0}-t e_{1}+(1-b)$ $s+p$, so $F(x) \equiv 0$. It shows that the probability of the government choosing a regulatory strategy is stable at any value.

(2) When $y \neq y^{*}=t e_{0}-c_{1}+p-z b s / t e_{0}-t e_{1}+(1-b) s$ $+p$ and $F(x)=0$, so, $x=0$ and $x=1$. $x^{*}=0$ or $x^{*}=1$ is an evolutionarily stable state of government.

(3) According to the derivation result of $F(x)$, obviously $t e_{0}-t e_{1}+(1-b) s+p>0$ only needs to discuss the positive and negative of $t e_{0}-c_{1}+p-z b s$ value, so it can be divided into the following two cases for discussion:(1)when $y>y^{*}=t e_{0}-c_{1}+p-z b s / t e_{0}-$ $t e_{1}+(1-b) s+p,\left.F^{\prime}(x)\right|_{x=0}<0,\left.F^{\prime}(x)\right|_{x=1}>0, x^{*}=$ 0 is the gradual stability of the government; (2) when $y<y^{*}=t e_{0}-c_{1}+p-z b s / t e_{0}-t e_{1}+(1-b) s+p$, $\left.F^{\prime}(x)\right|_{x=0}>0$, and $\left.F^{\prime}(x)\right|_{x=1}<0, x^{*}=1$ is the gradual stability of the government.

According to the above analysis, the evolution process of the government's stable state is obtained, as shown in Figure 1.

In Figure 1, there is a point $A=t e_{0}-c_{1}+p / b s$ and $B=$ $t e_{0}-c_{1}+p-b s / t e_{0}-t e_{1}+(1-b) s+f$, where Figure 1(a) is the probability distribution of the government choosing different strategies when $y=y^{*}=t e_{0}-c_{1}+p-z b s / t e_{0}-$ $t e_{1}+(1-b) s+p$. Figure $1(\mathrm{~b})$ is the case of $y>y^{*}=t e_{0}-$ $c_{1}+p-z b s / t e_{0}-t e_{1}+(1-b) s+p$, where $x^{*}=0$ is the gradual stability of the government; Figure 1(c) is the case of $y<y^{*}=t e_{0}-c_{1}+p-z b s / t e_{0}-t e_{1}+(1-b) s+p$, where $x^{*}=1$ is the gradual stability of the government.
4.2. Stability Analysis of Evolution Game of Express Enterprises. According to the evolutionary game theory, when $F^{\prime}\left(y^{*}\right)<0, y^{*}$ is the evolutionary stability strategy of express enterprises (ESS). The following is an analysis of the evolution and stability of express enterprises in different situations. According to the replication dynamic equation (2) of express enterprises, the derivative with respect to $y$ is $F^{\prime}(y)=(1-2 y)\left[x\left(t e_{0}-t e_{1}+(1-b) s+p\right)+z\left(R_{1}+R_{2}\right)-\right.$ $\left.R_{1}-c\right]$, so $F^{\prime}(y)=0, z^{*}=R_{1}+c-x\left[t e_{0}-t e_{1}+(1-b) s+\right.$ $p] / R_{1}+R_{2}$.

(1) When $z=z^{*}=R_{1}+c-x\left[t e_{0}-t e_{1}+(1-b) s+p\right] /$ $R_{1}+R_{2}$, so $F(y) \equiv 0$. It shows that the probability of the express enterprise to choose the implementation strategy is stable at any value.

(2) When $z \neq z^{*}=R_{1}+c-x\left[t e_{0}-t e_{1}+(1-b) s+p\right] /$ $R_{1}+R_{2}$ and $F(y)=0$, so, $y=0$ and $y=1 . y^{*}=0$ or $y^{*}=1$ is an evolutionarily stable state of the express enterprise.

(3) According to the derivation result of $F(y)$, obviously $R_{1}+R_{2}>0$, only needs to discuss the positive and negative of $R_{1}+c-x\left[t e_{0}-t e_{1}+(1-b) s+p\right]$ value, so it can be divided into the following two cases for discussion: (1) when $z>z^{*}=R_{1}+c-x\left[t e_{0}-t e_{1}+(1\right.$ $-b) s+p] / R_{1}+R_{2},\left.F^{\prime}(y)\right|_{y=0}>0$, and $\left.F^{\prime}(y)\right|_{y=1}<0$, $y^{*}=1$ is the gradual stability of the express enterprise; (2) when $z<z^{*}=R_{1}+c-x\left[t e_{0}-t e_{1}+(1-b) s\right.$ $+p] / R_{1}+R_{2},\left.F^{\prime}(y)\right|_{y=0}<0$, and $\left.F^{\prime}(y)\right|_{y=1}>0, y^{*}=$ 0 is the gradual stability of the express enterprise.

According to the above analysis, the evolution process of the stable state of express enterprises is obtained, as shown in Figure 2.

In Figure 2, there is a point $C=R_{1}+c / t e_{0}-t e_{1}+(1-$ b) $s+p$ and $D=R_{1}+c-\left[t e_{0}-t e_{1}+(1-b) s+p\right] / R_{1}+R_{2}$, where Figure $2(a)$ is the probability distribution of express enterprise choosing different strategies when $z=z^{*}=R_{1}+$ $c-x\left[t e_{0}-t e_{1}+(1-b) s+p\right] / R_{1}+R_{2}$. Figure $2(\mathrm{~b})$ is the case of $z>z^{*}=R_{1}+c-x\left[t e_{0}-t e_{1}+(1-b) s+p\right] / R_{1}+R_{2}$, and $y^{*}=1$ is the gradual stability of express enterprise; Figure 2(c) is the case of $z<z^{*}=R_{1}+c-x\left[t e_{0}-t e_{1}+(1-\right.$ b) $s+p] / R_{1}+R_{2}$, and $y^{*}=0$ is the gradual stability of the express enterprise.

4.3. Stability Analysis of Consumer Evolutionary Game. According to the evolutionary game theory, when $F^{\prime}\left(z^{*}\right)$ $<0$, where $z^{*}$ is the evolutionary stability strategy of consumers (ESS). The following is an analysis of the evolution and stability of consumers in different situations. According to the replication dynamic equation (3) of consumer, the derivative with respect to $z$ is $F^{\prime}(z)=(1-2 z)\left[y\left(R_{3}-c_{3}\right)+\right.$ $\left.x b s+R_{4}-c_{4}-R_{3}+c_{3}\right]$, so $F^{\prime}(z)=0, y^{*}=R_{3}-c_{3}-R_{4}+$ $c_{4}-x b s / R_{3}-c_{3}$. 


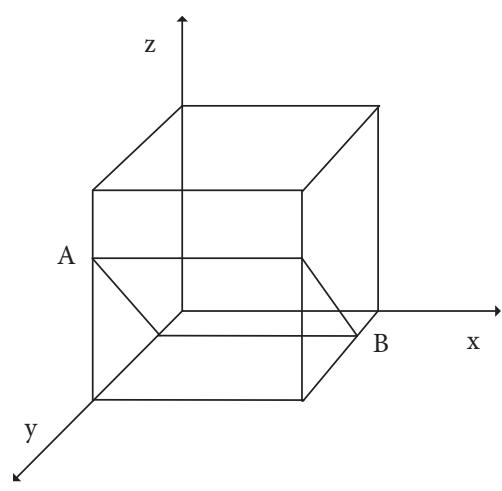

(a)

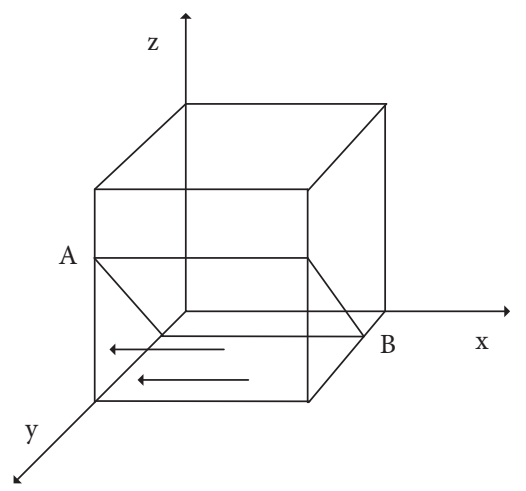

(b)

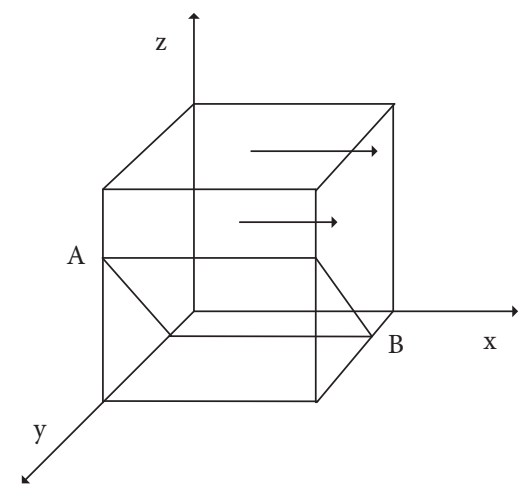

(c)

Figure 1: Evolution process of government decision-making.

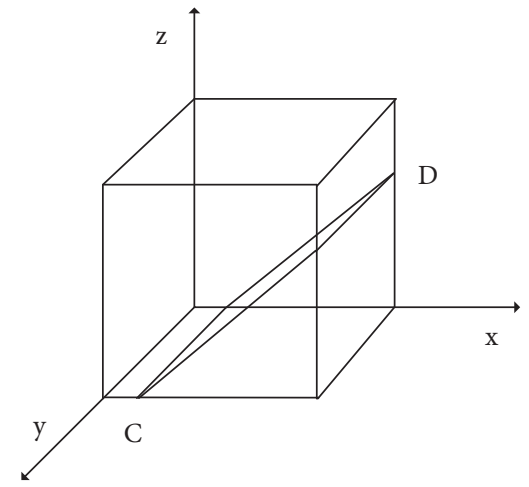

(a)

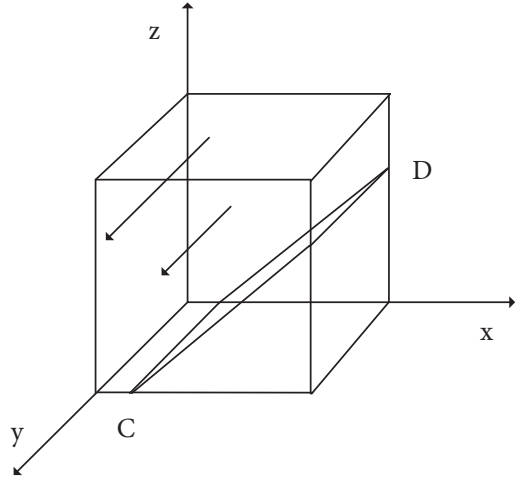

(b)

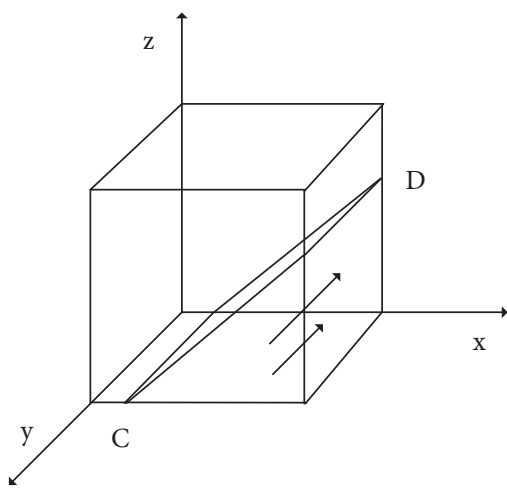

(c)

Figure 2: Evolution process of express enterprise decision-making.

(1) When $y=y^{*}=R_{3}-c_{3}-R_{4}+c_{4}-x b s / R_{3}-c_{3}$, so $F(z) \equiv 0$. It shows that the probability of consumers choosing the implementation strategy is stable at any value.

(2) When $y>y^{*}=R_{3}-c_{3}-R_{4}+c_{4}-x b s / R_{3}-c_{3}$, and $F(z)=0$, so, $z=0$ and $z=1$. $z^{*}=0$ or $z^{*}=1$ is an evolutionarily stable state of the consumer.

(3) According to the derivation result of $F(z)$, obviously $R_{3}-c_{3}>0$ only needs to discuss the positive and negative of $R_{3}-c_{3}-R_{4}+c_{4}-x b s$ value, so it can be divided into the following two cases for discussion: (1) when $y>y^{*}=R_{3}-c_{3}-R_{4}+c_{4}-x b s / R_{3}-c_{3}$, $\left.F^{\prime}(z)\right|_{z=0}>0$, and $\left.F^{\prime}(z)\right|_{z=1}<0, z^{*}=1$ is the gradual stability of consumer. (2) When $y<y^{*}=R_{3}-c_{3}-$ $R_{4}+c_{4}-x b s / R_{3}-c_{3},\left.F^{\prime}(z)\right|_{z=0}<0$, and $\left.F^{\prime}(z)\right|_{z=1}>$ $0, z^{*}=0$ is the gradual stability of consumer.

According to the above analysis, the evolution process of the stable state of consumers is obtained, as shown in Figure 3.
In Figure 3, there is a point $E=R_{3}-c_{3}-R_{4}+c_{4}-b s /$ $R_{3}-c_{3}$ and $F=R_{3}-c_{3}-R_{4}+c_{4} / b s$, where Figure $3(\mathrm{a})$ is the probability distribution of consumers choosing different strategies when $y=y^{*}=R_{3}-c_{3}-R_{4}+c_{4}-x b s / R_{3}-c_{3}$. Figure 3(b) is the case of $y>y^{*}=R_{3}-c_{3}-R_{4}+c_{4}-x b s / R_{3}$ $-c_{3}$, where $z^{*}=1$ is the gradual stability of consumer; Figure $3(\mathrm{c})$ is the case of $y<y^{*}=R_{3}-c_{3}-R_{4}+c_{4}-x b s /$ $R_{3}-c_{3}$, where $z^{*}=0$ is the gradual stability of consumer.

\section{Analysis of the Evolutionary Stability Strategy of Government, Consumers, and Express Enterprises}

It can be seen from the above theorem that simultaneous formulae (1)-(3) yield formula (6).

$$
\left\{\begin{array}{l}
F(x)=x(1-x)\left[y\left(t e_{1}-t e_{0}-(1-b) s-p\right)-z b s+\left(t e_{0}-c_{1}+p\right)\right] \\
F(y)=y(1-y)\left[x\left(t e_{0}-t e_{1}+(1-b) s+p\right)+z\left(R_{1}+R_{2}\right)-R_{1}-c\right] \\
F(z)=z(1-z)\left[y\left(R_{3}-c_{3}\right)+x b s+R_{4}-c_{4}-R_{3}+c_{3}\right]
\end{array}\right.
$$




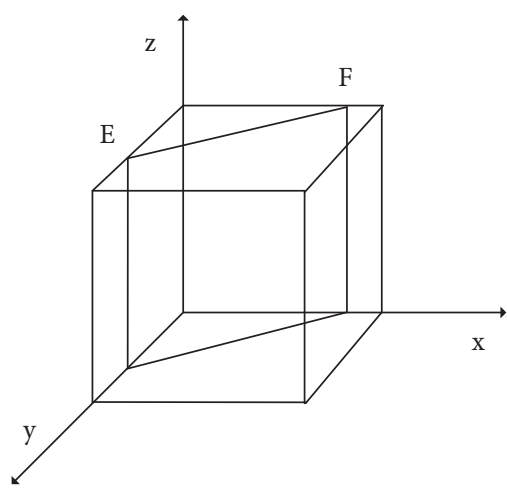

(a)

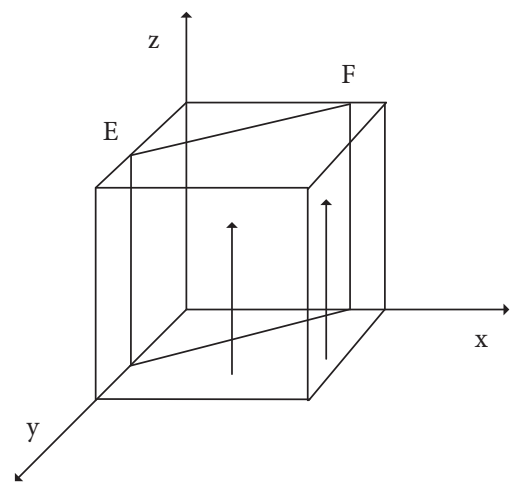

(b)

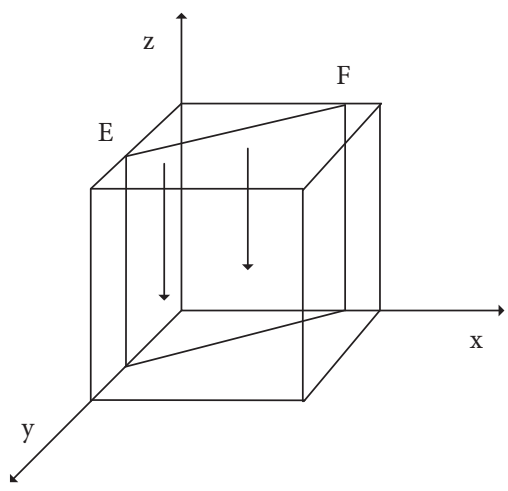

(c)

FIGURE 3: Evolution process of consumer decision-making.

Let $F(x)=F(y)=F(z)=0$ in formula (6); we can get that eight points are asymptotically stable, which are $E_{1}(0,0,0), E_{2}(1,0,0), E_{3}(0,1,0), E_{4}(0,0,1), E_{5}(1,1,0)$, $E_{6}(1,0,1), E_{7}(0,1,1)$, and $E_{8}(1,1,1)$, respectively, and the other points are not asymptotically stable. And the Jacobian matrix of the system can be obtained from equation (4) as follows:

$J=\left[\begin{array}{ccc}(1-2 x)\left[y\left(t e_{1}-t e_{0}-(1-b) s-p\right)-z b s+\left(t e_{0}-c_{1}+p\right)\right] & x(1-x)\left[t e_{1}-t e_{0}-(1-b) s-p\right] & -x(1-x) b s \\ y(1-y)\left(t e_{0}-t e_{1}+(1-b) s+p\right) & (1-2 y)\left[x\left(t e_{0}-t e_{1}+(1-b) s+p\right)+z\left(R_{1}+R_{2}\right)-R_{1}-c\right] & y(1-y)\left(R_{1}+R_{2}\right) \\ z(1-z) b s & z(1-z)\left(R_{3}-c_{3}\right) & (1-2 z)\left[y\left(R_{3}-c_{3}\right)+x b s+R_{4}-c_{4}-R_{3}+c_{3}\right]\end{array}\right]$.

The eigenvalues of each point are obtained by substituting the points into the Jacobian matrix, as shown in Table 3.

According to the assumptions and reality, if the government does not supervise, express enterprises will not take the initiative to implement the strategy of low-carbon express service; when $x=0$, the low-carbon service of express enterprises is $y=0$. At this time, consumers can only choose not to buy strategy but maintain the status quo, cannot achieve the goal of low-carbon development, and reduce carbon emissions of express enterprises. Therefore, this paper does not consider the case of equilibrium points $E_{1}, E_{3}, E_{4}$, and $E_{7}$ but only the case of equilibrium points $E_{2}, E_{5}, E_{6}$, and $E_{8}$. Because there are many parameter variables in the model, in order to analyze the sign of each eigenvalue easily and not lose generality, assuming $t e_{1}-c_{1}-s>0$, the carbon tax levied by the government on the express enterprises implementing the low-carbon service strategy is greater than the sum of the government's regulatory cost and the subsidy of the express enterprises implementing the low-carbon strategy; that is, the government's regulatory revenue is greater than the cost. The equilibrium points $E_{2}, E_{5}, E_{6}$, and $E_{8}$ in four different cases are discussed below.

5.1. E8 Is the Case of Evolutionary Stability Strategy of the System. As shown in Table 4, when $t e_{0}-t e_{1}+(1-b) s+$ $p-R_{1}-c>0$ and $b s+R_{4}-c_{4}-R_{3}+c_{3}>0$, the eigenvalues corresponding to the equilibrium point $E_{8}(1,1,1)$ are all negative. $E_{8}(1,1,1)$ is the only evolutionarily stable strategy of the system, namely, strategy combination (supervision, implementation, purchase). When the government supervises, if the total income of the express enterprises choosing to implement the low-carbon express service strategy is greater than the total income of the express enterprises not implementing the low-carbon express service strategy, the express enterprises will choose to implement the strategy. And when consumers choose to buy low-carbon express service strategy, the total revenue is greater than the total revenue of not buying a low-carbon express service, and consumers will also take the initiative to choose the purchase strategy.

As shown in Table 5, when $t e_{0}-t e_{1}+(1-b) s+p-R_{1}-$ $c>0$ and $b s+R_{4}-c_{4}-R_{3}+c_{3}<0$, the eigenvalues corresponding to the equilibrium point $E_{8}(1,1,1)$ are all negative, $E_{8}(1,1,1)$ is the only evolutionarily stable strategy of the system, namely, strategy combination (supervision, implementation, purchase). When the government supervises, if the total income of the express enterprises choosing to implement the low-carbon express service strategy is greater than the total income of the express enterprises not implementing the low-carbon express service strategy, the express enterprises will choose to implement the strategy. However, when consumers choose to buy a low-carbon express service strategy, the total revenue is less than the total revenue of not buying a low-carbon express service strategy, and consumers will choose not to buy strategy 
TABLE 3: Eigenvalues of equilibrium point.

\begin{tabular}{lccc}
\hline Equilibrium point & Characteristic value $\lambda_{1}$ & Characteristic value $\lambda_{2}$ & Characteristic value $\lambda_{3}$ \\
\hline$E_{1}(0,0,0)$ & $t e_{0}-c_{1}+p$ & $-R_{1}-c$ & $R_{4}-c_{4}-R_{3}+c_{3}$ \\
$E_{2}(1,0,0)$ & $-\left(t e_{0}-c_{1}+p\right)$ & $t e_{0}-t e_{1}+(1-b) s+p-R_{1}-c$ & $b s+R_{4}-c_{4}-R_{3}+c_{3}$ \\
$E_{3}(0,1,0)$ & $t e_{1}-c_{1}-(1-b) s$ & $-\left(-R_{1}-c\right)$ & $R_{4}-c_{4}$ \\
$E_{4}(0,0,1)$ & $t e_{0}-c_{1}+p-b s$ & $R_{2}-c$ & $-\left(R_{4}-c_{4}-R_{3}+c_{3}\right)$ \\
$E_{5}(1,1,0)$ & $-\left[t e_{1}-c_{1}-(1-b) s\right]$ & $-\left[t e_{0}-t e_{1}+(1-b) s+p-R_{1}-c\right]$ & $b s+R_{4}-c_{4}$ \\
$E_{6}(1,0,1)$ & $-\left(t e_{0}-c_{1}+p-b s\right)$ & $t e_{0}-t e_{1}+(1-b) s+p+R_{2}-c$ & $-\left(b s+R_{4}-c_{4}-R_{3}+c_{3}\right)$ \\
$E_{7}(0,1,1)$ & $t e_{1}-c_{1}-s$ & $-\left(R_{2}-c\right)$ & $-\left(R_{4}-c_{4}\right)$ \\
$E_{8}(1,1,1)$ & $-\left(t e_{1}-c_{1}-s\right)$ & $-\left[t e_{0}-t e_{1}+(1-b) s+p+R_{2}-c\right]$ & $-\left(b s+R_{4}-c_{4}\right)$ \\
\hline
\end{tabular}

TABLE 4: Evolutionary stability strategy of the equilibrium point.

\begin{tabular}{lcccc}
\hline Equilibrium point & $\lambda_{1}$ & $\lambda_{2}$ & $\lambda_{3}$ & Stability \\
\hline$E_{2}(1,0,0)$ & - & + & + & Unstable points \\
$E_{5}(1,1,0)$ & - & - & + & Unstable points \\
$E_{6}(1,0,1)$ & - & + & - & Unstable points \\
$E_{8}(1,1,1)$ & - & - & - & ESS \\
\hline
\end{tabular}

TABLE 5: Evolutionary stability strategy of the equilibrium point.

\begin{tabular}{lcccc}
\hline Equilibrium point & $\lambda_{1}$ & $\lambda_{2}$ & $\lambda_{3}$ & Stability \\
\hline$E_{2}(1,0,0)$ & - & + & - & Unstable points \\
$E_{5}(1,1,0)$ & - & - & + & Unstable points \\
$E_{6}(1,0,1)$ & - & + & + & Unstable points \\
$E_{8}(1,1,1)$ & - & - & - & $E S S$ \\
\hline
\end{tabular}

because the express enterprises will choose to implement the strategy in the pursuit of maximum benefits, so there is no traditional express service mode in the market, and consumers have no redundant choice and passively choose to buy low-carbon express service strategy.

5.2. E6 Is the Case of Evolutionary Stability Strategy of the System. As shown in Table 6, when $t e_{0}-t e_{1}+(1-b) s+p+$ $R_{2}-c<0$ and $b s+R_{4}-c_{4}-R_{3}+c_{3}>0$, the eigenvalues corresponding to the equilibrium point $E_{6}(1,0,1)$ are all negative, and $E_{6}(1,0,1)$ is the only evolutionarily stable strategy of the system, namely, strategy combination (supervision, nonimplementation, purchase). When the difference between the total cost of the carbon tax and cost minus subsidy of low-carbon express service and the total cost of the carbon tax, penalty, and penalty of no low-carbon express service is less than zero, express enterprises choose not to implement the strategy. However, when consumers choose to buy low-carbon express service strategy, the total revenue is greater than the total revenue of not buying a low-carbon express service, and express enterprises will choose the purchase strategy.

5.3. E2 Is the Case of Evolutionary Stability Strategy of the System. As shown in Table 7, when $t e_{0}-t e_{1}+(1-b) s+$ $p+R_{2}-c<0$ and $b s+R_{4}-c_{4}-R_{3}+c_{3}<0$, the eigenvalues corresponding to the equilibrium point $E_{2}(1,0,0)$ are all negative, and $E_{2}(1,0,0)$ is the only evolutionarily stable strategy of the system, namely, strategy combination (supervision, nonimplementation, nonpurchase). When the
TABLE 6: Evolutionary stability strategy of the equilibrium point.

\begin{tabular}{lcccc}
\hline Equilibrium point & $\lambda_{1}$ & $\lambda_{2}$ & $\lambda_{3}$ & Stability \\
\hline$E_{2}(1,0,0)$ & - & - & + & Unstable points \\
$E_{5}(1,1,0)$ & - & + & + & Unstable points \\
$E_{6}(1,0,1)$ & - & - & - & $E S S$ \\
$E_{8}(1,1,1)$ & - & + & - & Unstable points \\
\hline
\end{tabular}

TABLE 7: Evolutionary stability strategy of the equilibrium point.

\begin{tabular}{lcccc}
\hline Equilibrium point & $\lambda_{1}$ & $\lambda_{2}$ & $\lambda_{3}$ & Stability \\
\hline$E_{2}(1,0,0)$ & - & - & - & ESS \\
$E_{5}(1,1,0)$ & - & + & + & Unstable points \\
$E_{6}(1,0,1)$ & - & - & + & Unstable points \\
$\mathrm{E}_{8}(1,1,1)$ & - & + & - & Unstable points \\
\hline
\end{tabular}

difference between the total cost of the carbon tax and cost minus subsidy when the express enterprises choose to implement the low-carbon express service strategy and the sum of the carbon tax, penalty, and cost when the express enterprises do not implement the low-carbon express service is less than zero, the express enterprises choose not to implement the strategy. When the total revenue of consumers choosing to buy low-carbon express service is less than the total revenue of not buying low-carbon express service, consumers choose not to buy strategy.

Through the analysis of the above four cases, we can see that under the supervision of the government, we should protect the interests of express enterprises, because express enterprises, as the main body of implementing low-carbon express service, bear the most important role in the express market. As the seller, express enterprises occupy the dominant position in the market. No matter how consumers' income is, consumers, as buyers, can only make a passive choice in the existing express enterprises. There is no other choice; they can only passively choose the purchase strategy. Therefore, the government needs to put more energy on the regulation of carbon emission reduction of express enterprises and urge express enterprises to speed up the implementation of low-carbon express services.

\section{Conclusions}

This paper uses the evolutionary game to build a tripartite evolutionary game model of government, express delivery enterprises, and consumers and analyzes the evolution 
process of game players under different conditions. There are the following conclusions. (1) When setting the carbon tax rate, the government can ignore the impact on consumers and give more consideration to the influencing factors of logistics enterprises, which is conducive to the formulation of carbon emission reduction policies for logistics enterprises. (2) When the government sets a lower carbon tax rate, it can not only promote the carbon emission reduction of express enterprises but also be conducive to government supervision. (3) The evolution direction of the government's final decision will not change due to the size of $Y$ and $Z$, and the government's final decision is to adopt the regulatory strategy. This study provides theoretical guidance for the government to formulate a carbon tax policy, guides consumers to buy low-carbon services, and promotes carbon emission reduction of logistics enterprises. It shows that the factors influencing the decision-making of express enterprises are not only the government but also the consumers. Therefore, express enterprises need to consider the behavior of the government and consumers at the same time to decide the implementation strategy, which further shows that it is limited to only consider the external factors of government regulation when studying the low-carbon emission reduction of express enterprises. While supervising the carbon emission reduction of express enterprises, the government should strengthen the publicity and education of consumers' low-carbon knowledge.

\section{Data Availability}

No data were used to support this study.

\section{Conflicts of Interest}

The authors declare that they have no conflicts of interest.

\section{References}

[1] Xi jinping delivered an important speech at the seventy-fifth general debate of the UN general assembly, 2020, https:// xinhuanet.com.

[2] B. Lin: How to promote carbon peak and carbon neutralization in the next five years| depth watching the two sessions, 2021, https://xinhuanet.com.

[3] Y. Yang and X. Y. Xu, "Study on the evolution of low carbon behavior of logistics enterprises considering carbon tax policy," Journal of Safety and Environment, vol. 21, no. 4, pp. 1750-1758, 2021.

[4] D. Pearce, "The role of carbon taxes in adjusting to global warming," The Economic Journal, vol. 101, no. 407, pp. 938-948, 1991.

[5] Y. Katsoulacos and A. Xepapadeas, "Environmental policy under oligopoly with endogenous market structure," The Scandinavian Journal of Economics, vol. 3, no. 97, pp. 411-420, 1995.

[6] N. Ahmad and A. Wyckoff, Carbon Dioxide Emissions Embodied in International Trade of Goods, OECD Publishing, Paris, France, 2003.

[7] W. Wissema and R. delllink, "Age analysis of the impact of a Carbon Energy tax on the lrish economy," Ecological Economics, vol. 61, no. 4, pp. 671-683, 2007.
[8] G. E. Metcalf, "Designing a carbon tax to reduce U.S. Greenhouse Gas emissions," Review of Environmental Economics and Policy, vol. 3, no. 1, pp. 63-83, 2009.

[9] B. B. F. Wittneben, "Exxon is right: let us re-examine our choice for a cap-and-trade system over a carbon tax," Energy Policy, vol. 37, no. 6, pp. 2462-2464, 2009.

[10] Q. Zhu and Y. Geng, "Drivers and barriers of extended supply chain practices for energy saving and emission reduction among Chinese manufacturers," Journal of Cleaner Production, vol. 40, no. 2, pp. 6-12, 2013.

[11] W. Yu and Z. Zhang, "Game Study on the feasibility and mode selection of China's carbon tax policy," China's population, resources and environment, vol. 23, no. 6, pp. 8-15, 2013.

[12] H. Tang, "Research on the game between government and enterprises in green supply chain under the background of low-carbon economy-Based on the goal of enterprise independent emission reduction," Contemporary economic science, vol. 41, no. 6, pp. 108-119, 2019.

[13] J. Xu, Dynamic Analysis of Vehicle Carbon Tax Policy Replication Based on Evolutionary Game, Guilin University of Electronic Science and Technology, Guilin, China, 2020.

[14] A. A. Batabyal, "Games governments play: an analysis of national environmental policy in an open economy* $[\mathrm{J}]$," The Annals of Regional Science, vol. 2, no. 32, pp. 237-251, 1998.

[15] C. F. Lee, S. J. Lin, and C. Lewis, "Analysis of the impacts of combining carbon taxation and emission trading on different industry sectors," Energy Policy, vol. 36, no. 2, pp. 722-729, 2008.

[16] C. K. Frank, "Prices vs. quantities; the effects on technology choice," Journal of Public Economics, vol. 92, no. 5-6, pp. 1275-1287, 2008.

[17] W. Lang and Q. Zheng, "The impact of carbon tax on China's regional economy," Tax and economy, vol. 6, pp. 88-94, 2016.

[18] J.-S. Lim and Y.-G. Kim, "Combining carbon tax and R\&D subsidy for climate change mitigation," Energy Economics, vol. 34, no. 34, pp. S496-S502, 2012.

[19] J. Meltzer, "A carbon tax as A driver of green technology innovation and the implications for international trade," Energy Law Journal, vol. 35, pp. 45-69, 2014.

[20] J. Guojun and L. Hu, "Evolutionary game analysis of enterprise carbon emission reduction considering carbon tax," Statistics and decision, vol. 12, pp. 58-62, 2015.

[21] Y. Yuyin and L. Jinxi, "The effect of governmental policies of carbon taxes and energy-saving subsidies on enterprise decisions in a two-echelon supply chain," Journal of Cleaner Production, vol. 181, no. 181, pp. 675-691, 2018.

[22] X. Wang, Closed Loop Supply Chain Pricing and Emission Reduction Decision Considering "Trade in" Subsidy under Carbon Trading Mechanism, Guizhou University of Finance and Economics, Guiyang, China, 2020.

[23] J. Wang, L. Han, D. Gao, and X. Xu, "Game Analysis between government and enterprises in the development of low carbon economy," Research on science and technology management, vol. 22, pp. 234-238, 2012.

[24] Q. Zhu, Y. Wang, and Y. Tian, "Evolutionary game analysis of carbon emission reduction between local governments and manufacturing enterprises based on system dynamics," $O p$ erations research and management, vol. 23 , no. 3 , pp. 71-82, 2014.

[25] Z. Chen and W. Wang, "Evolutionary game analysis of government and polluting enterprises under environmental tax system," Management Review, vol. 29, no. 5, pp. 226-236, 2017. 
[26] M. Liu, Z. Li, and J. Zhang, "Evolutionary game analysis of government enterprise low carbon strategy based on prospect theory," Research on science and technology management, vol. 37, no. 20, pp. 245-253, 2017.

[27] J. Jiao, J. Chen, and L. Li, "Evolutionary game analysis on the behavior of local governments and enterprises under the reward and punishment mechanism of carbon emission reduction," China management science, vol. 25, no. 10, pp. 140-150, 2017.

[28] C. Liu, T. Xia, and T. Yu, "Research on evolutionary game between government regulation and manufacturer production from a low-carbon perspective," China management science, vol. 27, no. 11, pp. 96-106, 2019.

[29] J. Chen and J. Chen, Journal of Wuhan University of Technology, vol. 42, no. 6, pp. 517-523, 2020.

[30] J. Xu and X. Lv, "Research on the evolution of decisionmaking behavior of government, manufacturing enterprises and consumer groups in low-carbon economy," Operations research and management, vol. 6, pp. 81-91, 2014.

[31] X. Sun and Q. Chang, "Research on the behavior of low carbon economy related subjects based on game theory and incentive compatibility principle," in Proceedings of the 16th Annual Conference of China Management Science, Taiyuan, China, 2014.

[32] Y. Tian, K. Govindan, and Q. Zhu, “A system dynamics model based on evolutionary game theory for green supply chain management diffusion among Chinese manufacturers," Journal of Cleaner Production, vol. 80, no. 80, pp. 96-105, 2014.

[33] J. Chang, L. Zhao, and J. Du, "Evolutionary game analysis and stability control of corporate environmental behavior based on system dynamics," Systems Engineering, vol. 35, no. 10, pp. 79-87, 2017.

[34] S. Wu, X. Sun, and P. Yang, "Game Analysis of government carbon emission regulation under dual governance system," China's population, resources and environment, vol. 27, no. 12, pp. 21-30, 2017.

[35] K. Li, K. Yin, and Y. Yang, "Research on low carbon consumption guidance mechanism under game analysis-the balance between consumers, enterprises and government," Business Economic Research, vol. 20, pp. 40-43, 2018.

[36] B. Lv, G. Zhang, Y. Liu, and M. Ji, "Nash game equilibrium model of closed-loop supply chain network considering carbon tax and product greenness," China population, resources and environment, vol. 29, no. 1, pp. 59-69, 2019.

[37] W. Tang, X. Yuan, and H. Na, "Optimal carbon tax proportion selection based on government enterprise game," Soft Science, vol. 34, no. 7, pp. 94-100, 2020.

[38] B. Liu, T. Li, and S.-B. Tsai, "Low carbon strategy analysis of competing supply chains with different power structures," Sustainability, vol. 9, no. 5, p. 835, 2017. 